\title{
Effects of Longterm Treatment with Bosentan and Iloprost on Nailfold Absolute Capillary Number, Fingertip Blood Perfusion, and Clinical Status in Systemic Sclerosis
}

\author{
Amelia Chiara Trombetta, Carmen Pizzorni, Barbara Ruaro, Sabrina Paolino, Alberto Sulli, \\ Vanessa Smith, and Maurizio Cutolo
}

ABSTRACT. Objective. To quantify in patients with systemic sclerosis (SSc) the absolute nailfold capillary number/mm (the absolute number of capillaries, observable in the first row, in $1 \mathrm{~mm}$ per field) and fingertip blood perfusion (FBP) during longterm therapy with the endothelin receptor antagonist bosentan (BOSE) and the synthetic analog of prostacyclin PGI $_{2}$ iloprost (ILO) by multiple diagnostic tools. Observed values were correlated with clinical outcomes.

Methods. Thirty patients with SSc already receiving intravenous ILO (80 $\mu \mathrm{g} /$ day) for 5 continuous days (every 3 mos) were recruited in the clinic. Fifteen patients continued such treatment (ILO group), while in 15 patients BOSE (125 mg twice/day) was added (ILO + BOSE group) because of the onset of pulmonary arterial hypertension or digital ulcers (DU). The followup period was 4 years (T0-T4). Every year the following were evaluated: absolute nailfold capillary number/mm by nailfold videocapillaroscopy, FBP by laser Doppler flowmetry, DU incidence, DLCO, systolic pulmonary arterial pressure (sPAP), renal arterial resistive index, and other biomarkers. From T2 to T4, laser speckled contrast analysis was added. Nonparametric tests were used for statistical analysis.

Results. Limited to the ILO + BOSE group, absolute capillary number/mm and FBP showed a progressive increase independently from other variables. In addition, during followup there was a significant reduction (80\%) in the incidence of new DU, whereas DLCO and sPAP did not worsen. Conclusion. The study shows in patients with SSc with up to 4 years of combined therapy a progressive significant recovery in structure and function of microvasculature linked to improved clinical outcomes, independent of disease severity. (First Release October 15 2016; J Rheumatol 2016;43:2033-41; doi:10.3899/jrheum.160592)

Key Indexing Terms:

$\begin{array}{lcr}\text { SYSTEMIC SCLEROSIS } & \text { NAILFOLD VIDEOCAPILLAROSCOPY } & \text { ILOPROST } \\ \text { LASER SPECKLED CONTRAST ANALYSIS } & \text { BLOOD FLOW } & \text { BOSENTAN }\end{array}$

Systemic sclerosis (SSc) development includes microvascular damage that progresses from capillary dilation to capillary loss and reactive angiogenesis, as detectable by nailfold videocapillaroscopy $(\mathrm{NVC})^{1}$. The process is systemic and determines multiple clinical manifestations, from the early appearance of Raynaud phenomenon (RP) through the formation of digital ulcers (DU) until severe organ involvement, and impairment of the patient's quality of life with interstitial lung disease (ILD), pulmonary arterial hypertension $(\mathrm{PAH})$, heart involvement, and scleroderma renal crisis, often leading to death ${ }^{2,3}$.

Significant capillary loss, observed at NVC, is peculiar of
From the Research Laboratory and Academic Division of Clinical Rheumatology, Department of Internal Medicine, University of Genoa, Genoa, Italy; Department of Rheumatology, Ghent University Hospital, Ghent University, Ghent, Belgium.

$V$. Smith is supported by a research grant of the Research FoundationFlanders (Belgium; FWO; Grant number: 1.5.217.13N) and is Senior Clinical Investigator of the Research Foundation - Flanders (Belgium, FWO).

A.C. Trombetta, MD, PhD, Trainee in Clinical and Experimental Immunology, Research Laboratory and Academic Division of Clinical Rheumatology, Department of Internal Medicine, University of Genoa; C. Pizzorni, MD, PhD, Assistant Professor of Rheumatology, Research Laboratory and Academic Division of Clinical Rheumatology, Department of Internal Medicine, University of Genoa; B. Ruaro, MD, Trainee in Rheumatology, Research Laboratory and Academic Division of Clinical Rheumatology, Department of Internal Medicine, University of Genoa;
S. Paolino, MD, Assistant Professor of Rheumatology, Research Laboratory and Academic Division of Clinical Rheumatology, Department of Internal Medicine, University of Genoa; A. Sulli, MD, Associate Professor of Rheumatology, Research Laboratory and Academic Division of Clinical Rheumatology, Department of Internal Medicine, University of Genoa; V. Smith, MD, PhD, Associate Professor of Rheumatology, Head of Clinics in Rheumatology, Ghent University Hospital, Ghent University; M. Cutolo, MD, Full Professor of Rheumatology, Research Laboratory and Academic Division of Clinical Rheumatology, Department of Internal Medicine, University of Genoa.

Address correspondence to Dr. M. Cutolo, Research Laboratory and Academic Division of Clinical Rheumatology, Department of Internal Medicine, IRCCS San Martino AOU, University of Genoa, Viale Benedetto XVn.6,16132 Genoa, Italy.E-mail: mcutolo@unige.it

Full Release article. For details see Reprints/Permissions at jrheum.org Accepted for publication August 25, 2016.

Personal non-commercial use only. The Journal of Rheumatology Copyright @ 2016 . All rights reserved. 
the "late" scleroderma pattern of microangiopathy and is mainly preceded by progressive capillary enlargement, microhemorrhages, and their collapse, leading to presence of large avascular areas ${ }^{4}$. The importance of capillary loss was already demonstrated by a simple and reliable prognostic index, capable of predicting digital trophic lesion development in SSc-related microvascular disease when evaluated as part of the semiquantitative NVC scoring ${ }^{5}$. Moreover, microvascular function and its alterations in SSc can be reliably assessed by laser Doppler flowmetry (LDF) and laser speckled contrast analysis (LASCA) by evaluating blood perfusion at fingertips or at larger body areas $6,7,8,9$.

The most frequently used drugs for treatment of complications in patients with SSc are vasoactive drugs (grade of recommendation: level IA evidence, derived from metaanalysis of randomized controlled trials). In particular, for severe RP and for prevention of DU onset and treatment of PAH, both intravenous (IV) prostanoid iloprost (ILO) and the dual endothelin-1 receptor antagonist (ERA) bosentan (BOSE) are used, respectively ${ }^{10}$. BOSE seems to block pathogenic activities of endothelin-1, the endothelial-derived mediator determining both vasoconstriction and fibrosis genes induction ${ }^{11,12,13,14}$.

Previous longterm followup studies showed that treatment with BOSE in combination with ILO interferes with the progression of nailfold microvascular damage, but evaluated through less-sensitive methods such as semiquantitative scoring of capillary number by NVC and fingertip blood perfusion (FBP) by $\mathrm{LDF}^{15,16}$.

The primary endpoints of our present study were to investigate the longterm ( $4 \mathrm{yrs}$ ) effects of BOSE and ILO-integrated treatment on microvasculature using the more sensitive nailfold absolute capillary number/mm (NVC) and FBP, quantified by both LDF (T0-T4) and LASCA (T2-T4). Secondary and exploratory endpoints were the relations among longterm effects of BOSE and ILO-integrated treatment on both microvasculature and organ damage outcomes (lung, right heart, renal artery, and inflammatory indices).

\section{MATERIALS AND METHODS}

A prospective, open-label, nonrandomized study was carried out, including 30 consecutive patients with SSc (diagnosis based on the LeRoy and Medsger criteria ${ }^{17}$ and later confirmed in all patients by the 2013 American College of Rheumatology/European League Against Rheumatism criteria ${ }^{18}$ ) followed at the Rheumatology Division of Genoa University (Italy). All patients were receiving cyclic IV ILO for severe secondary RP (average 80 $\mu \mathrm{g} /$ day for 5 continuous days, every $3 \mathrm{mos}$ ). Fifteen patients continued the ILO treatment for a further 4 years. The other 15 patients with SSc, following the development of DU (10/15) or the diagnosis of PAH (5/15; according to the European Society of Cardiology and European Respiratory Society guidelines, as well as the national recommendations for the diagnosis and treatment of pulmonary hypertension) or DU, started treatment with BOSE as additional therapy $(125 \mathrm{mg} /$ day for the first month, then $125 \mathrm{mg}$ twice a day if tolerated) for a further 4 years ${ }^{19}$. All other ongoing treatments (acetylsalicylic acid, proton pump inhibitors, antihypertensive drugs, immunosuppressants) were kept with minimal or no changes during the next 4 years.
Ethical approval was not required, in accordance with the policy of our institution.

Each patient underwent a complete clinical evaluation and laboratory biomarkers were taken [including erythrocyte sedimentation rate (ESR), C-reactive protein (CRP)] at baseline. All variables were evaluated yearly in the same season (spring: March 21 to June 20, summer: June 21 to September 22, autumn: September 23 to December 20, winter: December 21 to March 20) for each patient. Tests were microangiopathy by NVC, FBP at basal skin temperature and at $36^{\circ} \mathrm{C}$ by $\mathrm{LDF}$, new DU incidence, pulmonary function test with DLCO, systolic pulmonary arterial pressure (sPAP) through Doppler echocardiography, and renal artery resistive index (RI) through echo color Doppler analysis. Most of the patients also underwent LASCA in the last 3 followup years (T2-T4, from January 2012).

$\mathrm{NVC}$ was performed in each patient using an optical probe, equipped with a $200 \times$ contact lens connected to image analysis software (Videocap, DS Medica). One operator (CP) performed the NVC examination in all patients, the same day as the LDF. Capillary absolute number was obtained counting all capillary loops, observable in the first row, in $1 \mathrm{~mm}$ per field, over 32 NVC fields ( 8 fingers, 4 fields per finger, fingers $2-5$ of each hand). Other nailfold capillaries abnormalities were scored by a validated semiquantitative rating scale, in accordance with previous studies ${ }^{20,21,22}$.

LDF was performed by the Periflux System 5000 equipped with a thermostatic probe (Perimed) before the beginning of the scheduled ILO infusion. FBP was evaluated both at basal skin temperature and after probe heating at $36^{\circ} \mathrm{C}\left(\mathrm{FBP} 36^{\circ} \mathrm{C}\right)$, as previously described, and afterward the difference between the 2 values obtained $(\triangle \mathrm{FBP})$ was calculated ${ }^{6}$. The same operator (BR) performed the examinations. The patients stayed in a waiting room at $22^{\circ}-23^{\circ} \mathrm{C}$ for at least $30 \mathrm{~min}$ before the assessment. FBP was detected at the level of the second, third, fourth, and fifth fingertip bilaterally, and measurement was started $30 \mathrm{~s}$ after probe positioning on the central area of each fingertip, waiting for minimal variation of the perfusion wave. The recording was continued for 1 min per finger ${ }^{6}$. During recording, the patient was relaxed and in a noise-free environment. The average blood perfusion was then calculated by adding average perfusion values from the fingers together and then dividing the final value by finger number. The results were expressed as perfusion units (PU) ${ }^{6}$

LASCA (Pericam PSI, Perimed) was performed from the same operator (BR) at the level of the whole volar and dorsal regions of the hands for $30 \mathrm{~s}$ each. Subsequently, regions of interest were created at the second, third, fourth, and fifth fingertips bilaterally, and the average PU was calculated, as previously reported $8,23,24$

All patients were informed that their data would be used for possible studies/analyses and gave their consent when starting to be followed up at the clinic.

Statistical analysis. Data were analyzed using IBM SPSS Statistics, Version 21.0 (IBM Corp). Descriptive statistic was used to determine basic clinical features of the population. The Mann-Whitney U test was used to compare not normally distributed variables. The chi-square test for independence was used to study nominal variable variance. The Friedman test was used to calculate changes in the mean scores for continuous characters in the 5 timepoints (T0-T4). Cochran's Q test was used to calculate the difference in proportions of 3 or more dichotomous variables with repeated measures. Marginal homogeneity test was used to calculate the differences in repeated measures of categorical values with more than 2 outcomes.

\section{RESULTS}

Baseline patients' characteristics. Patients' baseline clinical variables are displayed in Table 1 . There were no significant seasonal differences concerning the timing of test performance. Moreover, there were no differences in age, sex, average RP, disease duration, and capillaroscopic patterns between the 2 treatment groups. There was a statistically significant difference between limited cutaneous $(\mathrm{lcSSc})$ and 
Table 1. Average values at baseline for clinical and instrumental variables. Values are mean \pm SD or n (\%) unless otherwise specified.

\begin{tabular}{|c|c|c|c|c|}
\hline Clinical Variables & Total & $\mathrm{ILO}+\mathrm{BOSE}$ & ILO & $\mathrm{p}$ \\
\hline Age, yrs & $69 \pm 12$ & $66 \pm 13$ & $71 \pm 11$ & 0.46 \\
\hline Sex, $n$ & $M=4, F=26$ & $\mathrm{M}=3, \mathrm{~F}=12$ & $M=1, F=14$ & 0.28 \\
\hline $1 \mathrm{cSSc}$ & $22 / 30(73.33)$ & $7 / 15(46.66)$ & $15 / 15(100)$ & \\
\hline Anti-Scl70 & $8 / 30(26.6)$ & $6 / 15(40)$ & $2 / 15(13.3)$ & $<0.0001$ \\
\hline Anticentromere & $17 / 30(56.6)$ & $4 / 15(26.6)$ & $13 / 15(86.6)$ & $<0.0001$ \\
\hline Average disease duration, yrs & $13 \pm 8.5$ & $14 \pm 9.2$ & $12 \pm 7.88$ & 0.85 \\
\hline \multicolumn{5}{|l|}{ Capillaroscopic pattern } \\
\hline Early & $6 / 15$ & $2 / 15$ & $4 / 15$ & 0.65 \\
\hline Active & $11 / 15$ & $4 / 15$ & $7 / 15$ & 0.24 \\
\hline Late & $13 / 15$ & $9 / 15$ & $4 / 15$ & 0.13 \\
\hline
\end{tabular}

Instrumental Variables

ILO + BOSE vs ILO, Average Values at T0

$\mathrm{p}$

Season of test performance

Spring

Summer

Autumn

Winter

Capillary absolute number

FBP, PU

FBP $36^{\circ} \mathrm{C}, \mathrm{PU}$

$\triangle \mathrm{FBP}, \mathrm{PU}$

LASCA F, PU

LASCA P, PU

$\begin{array}{cc}4 \text { vs } 7 & 0.5 \\ 1 \text { vs } 3 & \\ 2 \text { vs } 1 & \\ 4 \text { vs } 4 & \\ 6.8 \pm 1.3 \text { vs } 7.1 \pm 0.5 & 0.41 \\ 59.74 \pm 8.7 \text { vs } 86.59 \pm 12 & 0.087 \\ 96.47 \pm 51 \text { vs } 136.9 \pm 53 & 0.05 \\ 36.7 \pm 30 \text { vs } 50.3 \pm 29.7 & 0.16 \\ 77.6 \pm 42.6 \text { vs } 93.4 \pm 34.6 & 0.48 \\ 72.95 \pm 48.5 \text { vs } 97.6 \pm 36.6 & 0.15\end{array}$

ILO: iloprost; BOSE: bosentan; SSc: systemic sclerosis; dcSSc: diffuse cutaneous SSc; lcSSc: limited cutaneous SSc; ANA: antinuclear antibodies; RP: Raynaud phenomenon; FBP: fingertip blood perfusion; PU: perfusion units; LASCA: laser speckled contrast analysis.

diffuse cutaneous ( $\mathrm{dcSSc}$ ) form frequencies and autoantibody positivity in the 2 groups (Table 1). At baseline (T0), the ILO + BOSE group had slightly worse values for capillary absolute number, FBP, FBP $36^{\circ} \mathrm{C}, \triangle \mathrm{FBP}$, LASCA, DLCO, and sPAP than the ILO group (Table 1, and Supplementary Table 1, available online at jrheum.org).

In the ILO + BOSE group, 10 patients with SSc had current DU (Supplementary Table 1, available online at jrheum.org), and those patients with new DU had slightly higher perfusion values than those without DU $(61.7 \pm 37$ vs $55.8 \pm 28$ PU) because of active healing-associated vascularization. At T0, capillary number score was not significantly different in the 2 groups $(\mathrm{p}=0.49)$ and the same result could be observed for RI $(p=0.22)$, ESR $(p=0.47)$, and CRP $(p=$ 0.05 ; Supplementary Table 1, available online at jrheum.org). Variation of NVC variables during followup. In the ILO + BOSE group, absolute capillary number $/ \mathrm{mm}$ was found to have a $14.7 \%$ increase from T0 to T4 $(\mathrm{p}=0.01$; Figure $1 \mathrm{~A}$, and Supplementary Table 2 and Supplementary Figure 1, available online at jrheum.org). The difference was not significant for $\mathrm{T} 0$ versus $\mathrm{T} 1, \mathrm{~T} 2$, and $\mathrm{T} 3$, but it was when comparing T0 to T4. On the other hand, in the ILO group, absolute capillary number $/ \mathrm{mm}$ was found to have a $9.4 \%$ decrease from T0 to T4 (Figure 1A, and Supplementary Table 2, available online at jrheum.org). In this case, the difference among all timepoints was not significant.

Capillary number score significantly improved from $\mathrm{T} 0$ to T3 ( $p=0.025)$ and T4 ( $p=0.035)$, while no changes were detected from T0 to T1 and T2 and for overall followup timepoints in the ILO + BOSE group (Figure 1B).

In the ILO group, there was an overall (T0-T4) nonsignificant worsening in capillary number score. The variation was already significant from T0 to T1 $(\mathrm{p}=0.046)$, and then T0 to $\mathrm{T} 3(\mathrm{p}=0.046)$, but not for T0 versus T2 or T0 versus T4 (Figure 1C).

Mixed-model analysis showed in the ILO + BOSE group a significant effect of BOSE treatment as a fixed factor on absolute capillary number $/ \mathrm{mm}$ variation $(\mathrm{p}=0.009)$. Interestingly, a significant effect was also found for antibody specificity and capillary number variation [estimated marginal means, i.e., the mean values for capillary number adjusted for these covariates were 7.48 for anticentromere antibody (ACA)-positive patients and 6.03 for anti-Scl70positive patients].

In addition, in the ILO + BOSE group, significant correlations between the absolute capillary number/mm variation and the baseline NVC pattern (estimated marginal means for early $=9.5$, active $=6.7$, late $=6.3 ; \mathrm{p}=0.008)$ as well as with SSc subtype $(\mathrm{lcSSc}=7.6, \mathrm{dcSSc}=6.2 ; \mathrm{p}=0.025)$ were found.

$$
\text { Personal non-commercial use only. The Journal of Rheumatology Copyright } \subset \text { (2016. All rights reserved. }
$$



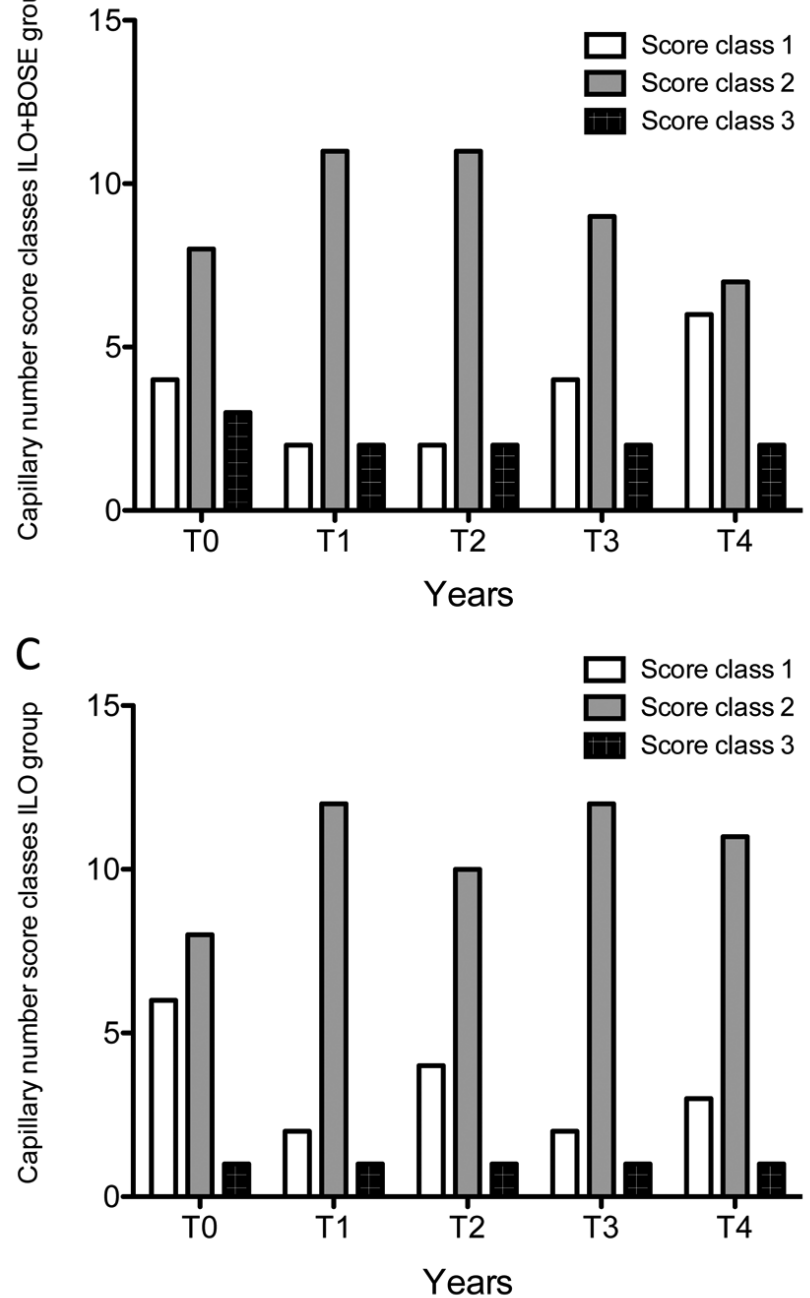

Adding in the model antibody specificity (ACA or anti-Sc170), baseline capillaroscopic pattern, and SSc subtype as fixed factors in the analysis, the significance of the BOSE treatment was still the major modifier $(p=0.027, p=0.036$,
Figure 1. A. Closed circles represent the ILO + BOSE group, and open circles represent the ILO group. In the ILO + BOSE group, absolute capillary number $/ \mathrm{mm}$ was found to have a $14.7 \%$ increase from $6.8 \pm 1.3$ (T0) to 7.8 $\pm 1.5(\mathrm{~T} 4), \mathrm{p}=0.01$. B. The bars represent the number of patients in each class $(1,2$, and 3 ) obtained through the capillary scoring (a semiquantitative rating scale to score capillary reduction: $1=$ less than $33 \%$ of normal capillary number, 2 = between $33 \%$ and $66 \%, 3=$ greater than $66 \%$, per linear millimeter). Capillary number score improved from T0 to T3 $(p=0.025)$ and T4 $(p=0.035)$ while no changes were detected from T0 to $\mathrm{T} 1(\mathrm{p}=0.18)$ and $\mathrm{T} 2(\mathrm{p}=0.18)$ and for overall followup timepoints $(p=0.77)$ in the ILO + BOSE group. C. In the ILO group, there was an overall (T0-T4) nonsignificant worsening in capillary number score $(\mathrm{p}=0.82)$. The variation was significant from T0 to T1 $(\mathrm{p}=0.046)$ and $\mathrm{T} 0$ to T3 $(\mathrm{p}=0.046)$, but not T0 vs T2 $(\mathrm{p}=0.15)$ and T0 vs T4 $(\mathrm{p}=0.083)$. ILO: iloprost; BOSE: bosentan.

and $p=0.005$ ). With all variables included in the model, the most significant effect was because of baseline NVC pattern $(p<0.0001)$, then SSc subtype $(p=0.001)$, and finally the type of treatment $(\mathrm{p}=0.06)$.

Variation of $L D F$ variables during followup. Of great interest, FBP at basal temperature in the ILO + BOSE group was found to have a $54.5 \%$ increase $(\mathrm{p}<0.0001)$ from $\mathrm{T} 0$ to $\mathrm{T} 4$, whereas in the ILO group, it was found to have a decrease of $22 \%$ from its initial value (Figure 2A, and Supplementary Table 2, available online at jrheum.org). In particular, in the ILO + BOSE group, the FBP difference was significant $(<0.05)$ among all timepoints for T0 versus T2, T3, and T4, and $\mathrm{T} 1$ versus $\mathrm{T} 3$ and T4. Similarly, $\mathrm{FBP}$ at $36^{\circ} \mathrm{C}$ showed a $7.8 \%$ increase from T0 to T4 $(\mathrm{p}=0.0001)$ in the ILO + BOSE group, but a $25.1 \%$ decrease from T0 to T4 $(p=0.0009)$ in the ILO group (Figure 2C, and Supplementary Table 2, available online at jrheum.org). In particular, the ILO + BOSE group showed a significant difference in $\mathrm{T} 0$ versus $\mathrm{T} 2$, T3, and T4. The ILO group showed a significant difference between $\mathrm{T} 0$ and $\mathrm{T} 3$ and $\mathrm{T} 4$.

Finally, $\triangle \mathrm{FBP}$ had a nonsignificant tendency to increase by $27 \%$ from T0 to T4 in the ILO + BOSE group, but to decrease by $38.8 \%$ from $\mathrm{T} 0$ to $\mathrm{T} 4$ in the ILO group (Figure $2 \mathrm{~B}$, and Supplementary Table 2, available online at jrheum.org).

The different treatments induced significant effects on the variation of FBP at basal temperature ( $p<0.0001$; Supplementary Table 2, available online at jrheum.org), on $\mathrm{FBP}$ at $36^{\circ} \mathrm{C}(\mathrm{p}=0.002)$, and on the $\triangle \mathrm{FBP}(\mathrm{p}=0.048)$. FBP, FBP $36^{\circ} \mathrm{C}$, and $\triangle \mathrm{FBP}$ variations did not correlate with antibody specificity (estimated marginal means for ACA: 66 PU, anti-Scl70: 77.7 PU).

Further, FBP, FBP $36^{\circ} \mathrm{C}$, and $\triangle \mathrm{FBP}$ observed values did not correlate in a statistically significant way with baseline NVC patterns (estimated marginal means for FBP early: 128 PU, active: $89 \mathrm{PU}$, late: $74 \mathrm{PU}, \mathrm{p}=0.17$; FBP $36^{\circ} \mathrm{C}$ early: 159 PU, active: 132 PU, late: $121 \mathrm{PU}, \mathrm{p}=0.54 ; \Delta \mathrm{FBP}$ : early: 20 PU, active: 36 PU, late: $48 \mathrm{PU}, \mathrm{p}=0.18)$. On the other hand, $\mathrm{FBP}, \mathrm{FBP} 36^{\circ} \mathrm{C}$, and $\triangle \mathrm{FBP}$ variations correlated with SSc subtype (estimated marginal means: FBP: $1 \mathrm{cSSc}=72.23$

Personal non-commercial use only. The Journal of Rheumatology Copyright @ 2016 . All rights reserved. 

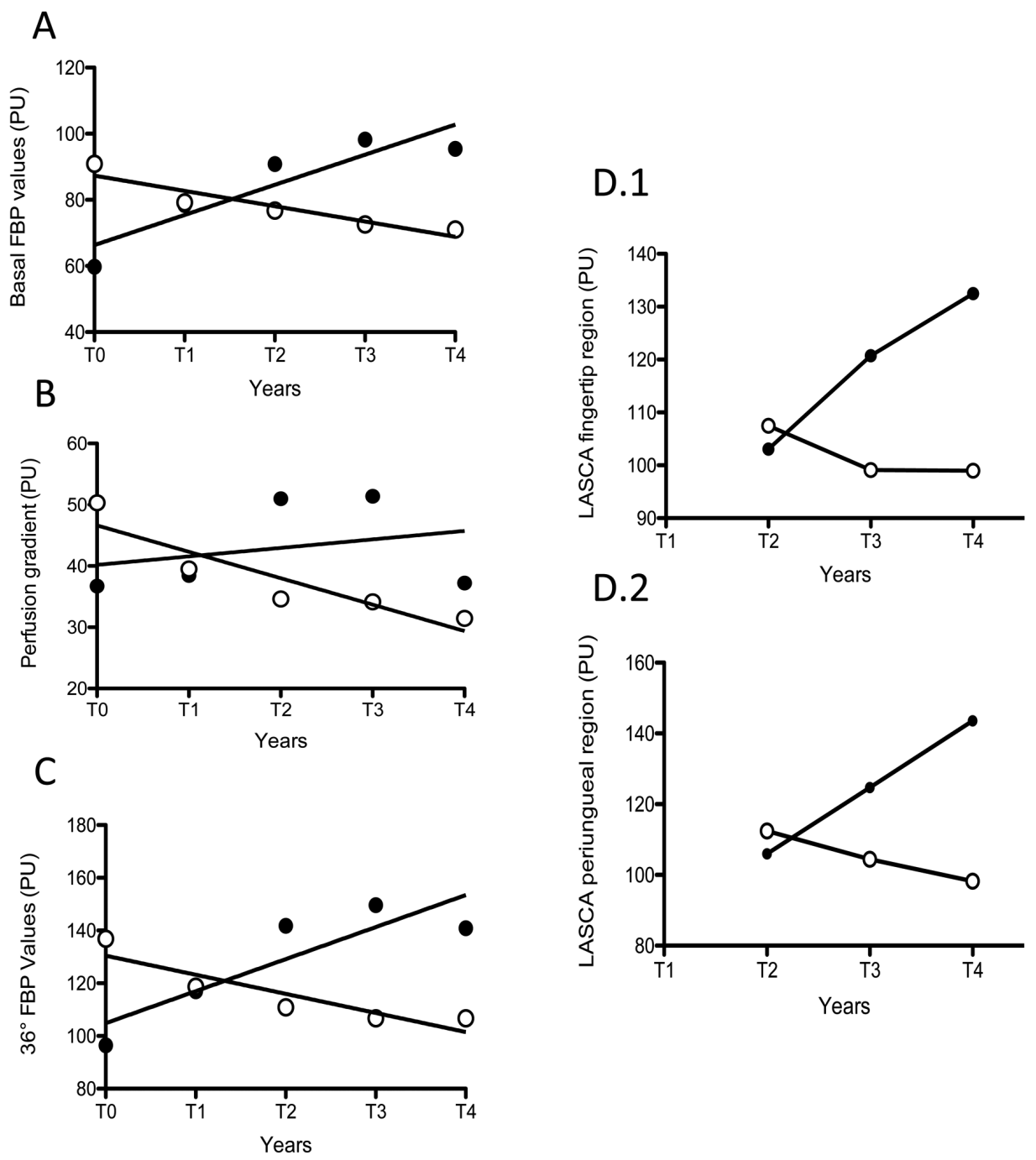

Figure 2. Closed circles represent the ILO + BOSE group, and open circles represent the ILO group. Perfusion studied by laser Doppler flowmetry at (A) basal temperature, (B) perfusion gradient, (C) at $36^{\circ} \mathrm{C}$, (D.1) LASCA of fingertip, and (D.2) LASCA of periungual region was higher throughout the followup in the ILO + BOSE group. ILO: iloprost; BOSE: bosentan; LASCA: laser speckled contrast analysis; FBP: fingertip blood perfusion; PU: perfusion units.

$\mathrm{PU}, \mathrm{dcSSc}=95 \mathrm{PU}, \mathrm{p}=0.042 ; \mathrm{FBP} 36^{\circ} \mathrm{C}: \mathrm{lcSSc}=107 \mathrm{PU}$, $\mathrm{dcSSc}=140 \mathrm{PU}, \mathrm{p}=0.047 ; \Delta \mathrm{FBP}: 1 \mathrm{cSSc}=30 \mathrm{PU}$, $\mathrm{dcSSc}=48 \mathrm{PU}, \mathrm{p}=0.044)$.

Finally, when the significant fixed factor of SSc subtype was included in the model, it did not change the influence exerted by treatment on baseline $\mathrm{FBP}(\mathrm{p}<0.0001)$, but influenced the FBP $36^{\circ} \mathrm{C}(\mathrm{p}=0.24)$ and $\triangle \operatorname{FBP}(\mathrm{p}=0.058)$.

Variation of LASCA during followup. LASCA of fingertips showed a statistically significant tendency to increase by $28.1 \%$ from $\mathrm{T} 2$ to $\mathrm{T} 4(\mathrm{p}=0.045)$ in the ILO + BOSE group, and a nonstatistically significant tendency to decrease by $7.5 \%$ from T2 to T4 in the ILO group (Figure 2D.1, and Supplementary Table 2 and Supplementary Figure 1, available online at jrheum.org).
Moreover, LASCA of the periungual region showed a tendency of PU to increase by $34.9 \%$ from T2 to T4 ( $\mathrm{p}=$ $0.05)$ in the ILO + BOSE group, and a nonsignificant tendency to decrease by $13 \%$ in the ILO group from T2 to T4 ( $=0.27$; Figure 2D.2 and Supplementary Table 2 and Supplementary Figure 1, available online at jrheum.org).

Variation of clinical variables during followup. In the course of the followup, a significant reduction (80\%) in the incidence of new DU in the ILO + BOSE group from T0 (10/15 patients) to T4 (2/15 patients) was observed (Cochran's Q statistics: chi-square $=17.28, \mathrm{p}=0.002$; Figure 3A).

DLCO did not change significantly in ILO + BOSE patients (increased by $9.1 \%, \mathrm{p}=0.46$ ) from $\mathrm{T} 0$ to $\mathrm{T} 4$, while 
A

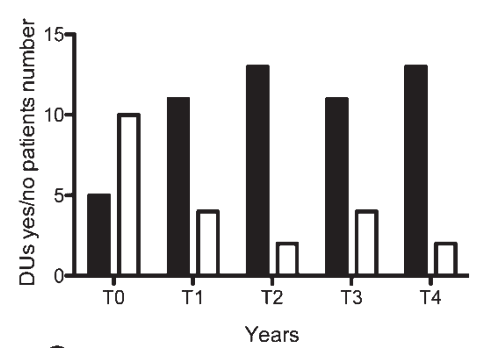

C
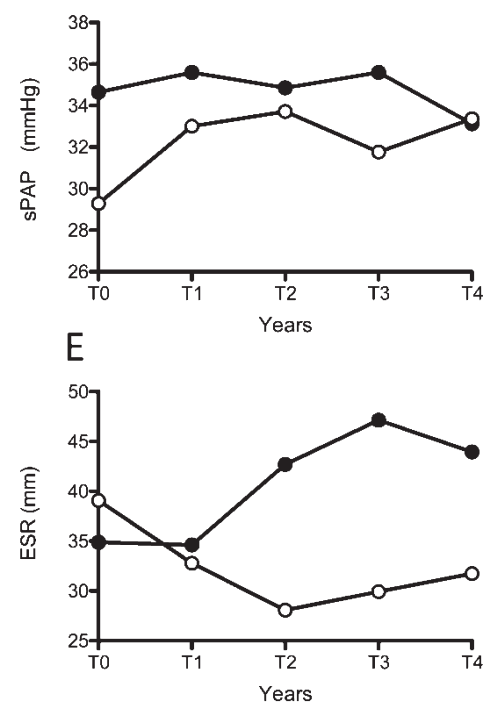

B

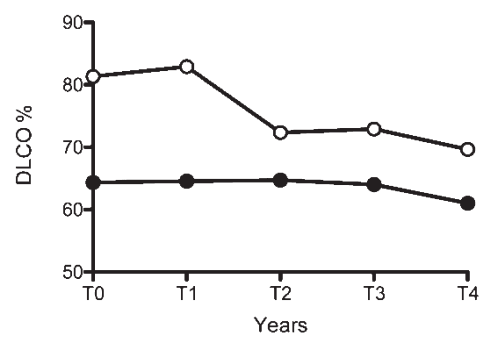

D

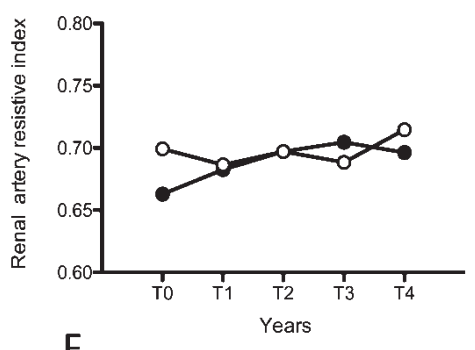

$\mathrm{F}$

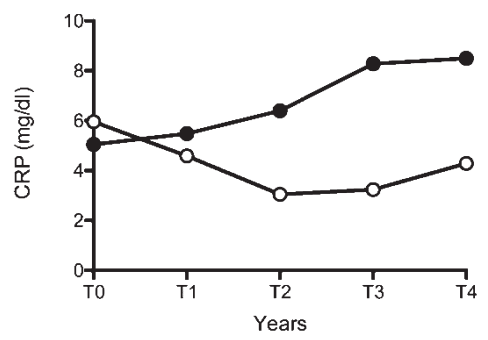

Figure 3. A. White bars represent patients with at least 1 new ulcer per year. Black bars represent patients with no ulcers (presence of pulmonary hypertension). There was a significant reduction $(80 \%)$ in the incidence of new DU in the ILO + BOSE group from T0 (10/15 patients) to T4 (2/15 patients) as indicated by Cochran's q statistics: chi-square $=17.28$ and $\mathrm{p}=0.002$. B. Closed circles represent the ILO + BOSE group, and open circles represent the ILO group. DLCO did not change significantly (increased by $9.1 \%, \mathrm{p}=0.46$ ) in ILO + BOSE patients from T0 $(64.3 \pm 16)$ to $\mathrm{T} 4(70.2 \pm 28)$, while it was gradually reduced by $8.1 \%$ ( $\mathrm{p}=$ $0.039)$ from $\mathrm{T} 0(81.3 \pm 16)$ to T4 $(74.7 \pm 24)$ in the ILO group. C. The sPAP did not change during followup in the ILO + BOSE group ( $\mathrm{T} 0=34.6 \pm 9, \mathrm{~T} 4=34.5 \pm 7.1, \mathrm{p}=0.8)$, while it gradually worsened by $15 \%$ (from $\mathrm{T} 0=29.3 \pm 3$ to $\mathrm{T} 4=33.7 \pm 6, \mathrm{p}=0.04$ ) in the ILO group. D. RI did not change significantly from T0 to T4 in either group. E. ESR did not change significantly from T0 to T4 in either group. F. CRP was higher throughout the followup in the ILO + BOSE group. Closed circles represent the ILO + BOSE group, and open circles represent the ILO group. DU: digital ulcers; ILO: iloprost; BOSE: bosentan; sPAP: systolic pulmonary arterial pressure; RI: renal arterial resistive index; ESR: erythrocyte sedimentation rate; CRP: C-reactive protein.

it was significantly reduced by $8.1 \%(\mathrm{p}=0.039)$ from $\mathrm{T} 0$ to T4 in the ILO group (Figure 3B, and Supplementary Table 1, available online at jrheum.org).

The sPAP did not change during the followup in the ILO + BOSE group, while it gradually worsened by $15 \%$ ( $\mathrm{p}=$ 0.04 ) in the ILO group (Figure 3C, and Supplementary Table 1 , available online at jrheum.org). RI and ESR did not change significantly from T0 to T4 in either group (Figure 3D-E, and Supplementary Table 1, available online at jrheum.org), while CRP was higher throughout the followup only in the ILO +
BOSE group (Figure 3F, and Supplementary Table 1, available online at jrheum.org).

Throughout the followup period, none of the patients had a significant rise in transaminase levels ( $>3 \times$ normal values).

Followup test timing. For most of the patients, the examinations were carried out yearly all in the same day or within a few days close in time. For this reason, there were no significant differences in overall seasonal frequency of test execution from spring to winter in either of the 2 groups: T0-T4 ILO + BOSE $(\mathrm{p}=0.83)$ and ILO $(\mathrm{p}=0.92)$. 
Moreover, there were no significant differences in timing of test execution for each followup year between the 2 groups: ILO + BOSE versus ILO T1 (p=0.82), T2 (p = 0.4), T3 (p = $0.3)$, and $\mathrm{T} 4(\mathrm{p}=0.25)$.

\section{DISCUSSION}

Our open-label, prospective study of 4 followup years suggests that longterm treatment with BOSE added to ILO administered quarterly in patients with SSc exerts a remodeling effect on structural and functional microvascular alterations, as well as on stabilization of lung functional status and DU progression compared with ILO monotherapy. This modifying activity on microcirculation seems to involve all SSc categories, independent from other individual characteristics.

Because capillary density observed at NVC is usually presented as a percentage or a ratio as part of the semiquantitative scoring system, in our present study the absolute capillary number/mm was evaluated to increase the sensitivity 15,21,22.

With this approach, a significant progressive increase of capillaries was detected in the group of patients treated with ILO + BOSE, despite a nonsignificant variation of the semiquantitative capillary scoring. On the contrary, in the group treated with ILO monotherapy, a progressive absolute capillary number/mm decrease was detected.

The simple count of nailfold capillaries/mm has been recently validated as the best biomarker to assess the severity of the microvascular damage and to predict DU incidence in $\mathrm{SSc}^{25}$.

The multivariate analysis showed that antibody specificity, baseline capillaroscopic pattern, and SSc subtype defined a group of patients with SSc in which the significance of BOSE effect was found more evident. In our present study, the highly significant data obtained from LDF and LASCA confirmed a strong remodeling effect exerted by longterm ERA treatment on microvascular alterations, mainly in patients with dcSSc${ }^{26}$. It has to be considered, according to a previous pilot study, that LASCA shows lower intraoperator variability versus LDF. In fact, FBP by LDF and LASCA were performed in 61 consecutive patients with SSc and 61 sex- and age-matched healthy subjects. The reproducibility of the technique was measured using the ICC and it was $88 \%$ for LDF (ICC $0.88,95 \%$ CI $0.83-0.91$ ) and $95 \%$ for LASCA technique (ICC $0.95,95 \%$ CI $0.94-0.97)^{7}$.

As a matter of fact, uni- and bivariate LDF analysis, both at basal skin temperature and after probe heating, showed an increase in peripheral perfusion in the ILO + BOSE group compared with the ILO group, already from the second year of followup. The tendency of $\triangle \mathrm{FBP}$ to increase in the ILO + BOSE group and to decrease in the ILO group confirms the influence exerted by the ERA treatment on microvasculature reactivity as also previously reported $6,16,26$.

The clinical analysis over 4 years confirmed the efficacy of BOSE in preventing new DU, which in turn are known to correlate with nailfold capillary number $5,11,25,27,28,29$.

Interestingly, regarding DU current status, patients with new DU showed higher perfusion values than those without, as previously observed ${ }^{27,30}$. This was attributed to the healing process, which could convey blood flux mainly to the ulcerated area, in those patients with limited vasculopathy ${ }^{27,30}$.

Lower DLCO and higher ESR values were defined in a prognostic model developed by Bryan, et al as clinical variables associated in SSc with a significant reduction of life expectancy, together with older age, male sex, and presence of urine protein ${ }^{31}$.

In our present study, the influence of BOSE on stabilization of DLCO and sPAP was observed, whereas a progressive worsening was detected in the ILO group. Previous experiences showed that BOSE treatment seems to decrease deterioration of lung function in patients with $\mathrm{PAH}$ by reducing vascular resistance in lung capillaries $32,33,34,35$.

In any case, both the ILO + BOSE and the ILO groups showed a stable renal artery resistive index throughout the 4 years of followup.

To date, ours is the first comprehensive 4-year followup study, to our knowledge, showing with multiple tools a progressive significant improvement induced by ERA in microvasculature structure and function, independent of disease severity and baseline SSc clinical characteristics.

Interestingly, a subgroup of patients with SSc, characterized by the presence of ACA specificity, early NVC pattern, and cutaneous SSc subtype, seems more likely to improve from the microvascular point of view after long-time BOSE treatment.

On the other hand, other authors observed no effect on microvascular structure and function when ERA treatment was administered to patients with SSc for short-term therapy and in monotherapy, probably because of a too-short interval between sequential NVC observations ${ }^{36,37,38}$.

The combination of BOSE + ILO studied here seems to exert a synergistic effect by increasing the possible interaction between the ERA and their targets, following an increased vasodilation (ILO) ${ }^{6}$.

Major limitations of our study are that it is an open-label, non-randomized study with a relatively small population of patients with SSc.

Mean age in the patient population was, from baseline, older than the usual age of presentation of patients with scleroderma (30-40 yrs). The main reason for this is that the average age in our geographical area is 47.8 years. For this reason, we can expect our patients to experience advanced disease complications and instrumental variable alterations. Nevertheless, we found 2 patient groups with no significant age differences ( $p=0.46$; Table 1$)$ so that we had the possibility to cut out this bias, comparing the 2 populations for other variables of interest.

For these reasons, we consider the study population Personal non-commercial use only. The Journal of Rheumatology Copyright @ 2016 . All rights reserved. 
completely representative of the actual conditions in all patients with scleroderma.

Concerning lung disease, we did not consider variables other than DLCO and SPAP, studied as continuous variables, assuming that it would be more useful to evaluate 2 numerical variables whose changes could be easily quantified from baseline to the end of the study and from 1 followup to another. Forced vital capacity reduction or radiological alterations peculiar to ILD were present in some of our patients (especially in those with higher sPAP values), but were not assessed here because they were considered less finely modulated compared with SPAP and DLCO ${ }^{39}$. Moreover, serial DLCO trends were considered the most important indicators of poor outcome in scleroderma lung disease ${ }^{40}$. Finally, we did not evaluate frequency and intensity of RP attacks.

Larger controlled treatment trials that consider the absolute capillary number $/ \mathrm{mm}$ and fingertip perfusion would be welcome in younger patients with SSc and in earlier disease stage.

\section{ACKNOWLEDGMENT}

Dr. Sara De Gregorio from the Division of Rheumatology, University of Genoa, supported data processing and graphic reproduction.

\section{ONLINE SUPPLEMENT}

Supplementary data for this article are available online at jrheum.org.

\section{REFERENCES}

1. Cutolo M, Sulli A, Smith V. Assessing microvascular changes in systemic sclerosis diagnosis and management. Nat Rev Rheumatol 2010;6:578-87.

2. Bérezné A, Seror R, Morell-Dubois S, de Menthon M, Fois E, Dzeing-Ella A, et al. Impact of systemic sclerosis on occupational and professional activity with attention to patients with digital ulcers. Arthritis Care Res 2011;63:277-85.

3. Wigley FM. Vascular disease in scleroderma. Clin Rev Allergy Immunol 2009;36:150-75.

4. Cutolo M, Sulli A, Pizzorni C, Accardo S. Nailfold videocapillaroscopy assessment of microvascular damage in systemic sclerosis. J Rheumatol 2000;27:155-60.

5. Smith V, De Keyser F, Pizzorni C, Van Praet JT, Decuman S, Sulli A, et al. Nailfold capillaroscopy for day-to-day clinical use: construction of a simple scoring modality as a clinical prognostic index for digital trophic lesions. Ann Rheum Dis 2011;70:180-3.

6. Cutolo M, Ferrone C, Pizzorni C, Soldano S, Seriolo B, Sulli A. Peripheral blood perfusion correlates with microvascular abnormalities in systemic sclerosis: a laser-Doppler and nailfold videocapillaroscopy study. J Rheumatol 2010;37:1174-80.

7. Ruaro B, Sulli A, Alessandri E, Pizzorni C, Ferrari G, Cutolo M. Laser speckle contrast analysis: a new method to evaluate peripheral blood perfusion in systemic sclerosis patients. Ann Rheum Dis 2014;73:1181-5.

8. Sulli A, Ruaro B, Cutolo M. Evaluation of blood perfusion by laser speckle contrast analysis in different areas of hands and face in patients with systemic sclerosis. Ann Rheum Dis 2014;73:2059-61.

9. Lambrecht V, Cutolo M, De Keyser F, Decuman S, Ruaro B, Sulli A, et al. Reliability of the quantitative assessment of peripheral blood perfusion by laser speckle contrast analysis in a systemic sclerosis cohort. Ann Rheum Dis 2016;75:1263-4.
10. Kowal-Bielecka O, Landewé R, Avouac J, Chwiesko S, Miniati I, Czirjak L, et al; EUSTAR Co-Authors. EULAR recommendations for the treatment of systemic sclerosis: a report from the EULAR Scleroderma Trials and Research group (EUSTAR). Ann Rheum Dis 2009;68:620-8.

11. Herrick AL. Contemporary management of Raynaud's phenomenon and digital ischaemic complications. Curr Opin Rheumatol 2011;23:555-61.

12. Abraham D, Distler O. How does endothelial cell injury start? The role of endothelin in systemic sclerosis. Arthritis Res Ther 2007;9 Suppl 2:S2.

13. Sulli A, Soldano S, Pizzorni C, Montagna P, Secchi ME, Villaggio B, et al. Raynaud's phenomenon and plasma endothelin: correlations with capillaroscopic patterns in systemic sclerosis. J Rheumatol 2009;36:1235-9.

14. Cutolo M, Montagna P, Brizzolara R, Smith V, Alessandri E, Villaggio B, et al. Effects of macitentan and its active metabolite on cultured human systemic sclerosis and control skin fibroblasts. J Rheumatol 2015;42:456-63.

15. Cutolo M, Zampogna G, Vremis L, Smith V, Pizzorni C, Sulli A Longterm effects of endothelin receptor antagonism on microvascular damage evaluated by nailfold capillaroscopic analysis in systemic sclerosis. J Rheumatol 2013;40:40-5.

16. Cutolo M, Ruaro B, Pizzorni C, Ravera F, Smith V, Zampogna G, et al. Longterm treatment with endothelin receptor antagonist bosentan and iloprost improves fingertip blood perfusion in systemic sclerosis. J Rheumatol 2014;41:881-6.

17. LeRoy EC, Medsger TA Jr. Criteria for the classification of early systemic sclerosis. J Rheumatol 2001;28:1573-6.

18. van den Hoogen F, Khanna D, Fransen J, Johnson SR, Baron M, Tyndall A, et al. 2013 classification criteria for systemic sclerosis: an American college of rheumatology/European league against rheumatism collaborative initiative. Ann Rheum Dis 2013; 72:1747-55.

19. Galiè N, Humbert M, Vachiery JL, Gibbs S, Lang I, Torbicki A, et al. 2015 ESC/ERS Guidelines for the diagnosis and treatment of pulmonary hypertension: The Joint Task Force for the Diagnosis and Treatment of Pulmonary Hypertension of the European Society of Cardiology (ESC) and the European Respiratory Society (ERS): Endorsed by: Association for European Paediatric and Congenital Cardiology (AEPC), International Society for Heart and Lung Transplantation (ISHLT). Eur Heart J 2016;37:67-119.

20. Trombetta AC, Smith V, Pizzorni C, Meroni M, Paolino S, Cariti C, et al. Quantitative alterations of capillary diameter have a predictive value for development of the capillaroscopic systemic sclerosis pattern. J Rheumatol 2016;43:599-606.

21. Sulli A, Secchi ME, Pizzorni C, Cutolo M. Scoring the nailfold microvascular changes during the capillaroscopic analysis in systemic sclerosis patients. Ann Rheum Dis 2008;67:885-7.

22. Smith V, Pizzorni C, De Keyser F, Decuman S, Van Praet JT, Deschepper E, et al. Reliability of the qualitative and semiquantitative nailfold videocapillaroscopy assessment in a systemic sclerosis cohort: a two-centre study. Ann Rheum Dis 2010;69:1092-6

23. Sulli A, Ruaro B, Alessandri E, Pizzorni C, Cimmino MA, Zampogna $\mathrm{G}$, et al. Correlations between nailfold microangiopathy severity, finger dermal thickness and fingertip blood perfusion in systemic sclerosis patients. Ann Rheum Dis 2014;73:247-51.

24. Ruaro B, Sulli A, Pizzorni C, Paolino S, Smith V, Cutolo M. Correlations between skin blood perfusion values and nailfold capillaroscopy scores in systemic sclerosis patients. Microvasc Res 2016;105:119-24.

25. Cutolo M, Herrick AL, Distler O, Becker M, Beltran E, Carpentier $\mathrm{P}$, et al. Nailfold videocapillaroscopic and other clinical risk factors for digital ulcers in systemic sclerosis: a multicenter, prospective 
cohort study. Arthritis Rheumatol 2016 Apr 25 (E-pub ahead of print).

26. Rosato E, Molinaro I, Borghese F, Rossi C, Pisarri S, Salsano F. Bosentan improves skin perfusion of hands in patients with systemic sclerosis with pulmonary arterial hypertension. J Rheumatol 2010;37:2531-9.

27. Korn JH, Mayes M, Matucci Cerinic M, Rainisio M, Pope J, Hachulla E, et al. Digital ulcers in systemic sclerosis: prevention by treatment with bosentan, an oral endothelin receptor antagonist. Arthritis Rheum 2004;50:3985-93.

28. Matucci-Cerinic M, Denton CP, Furst DE, Mayes MD, Hsu VM, Carpentier P, et al. Bosentan treatment of digital ulcers related to systemic sclerosis: results from the RAPIDS-2 randomised, double-blind, placebo-controlled trial. Ann Rheum Dis 2011; 70:32-8.

29. Steen V, Denton CP, Pope JE, Matucci-Cerinic M. Digital ulcers: overt vascular disease in systemic sclerosis. Rheumatology 2009;48:Suppl3:iii19-24.

30. Ambrózy E, Waczulíková I, Willfort A, Böhler K, Cauza K, Ehringer $\mathrm{H}$, et al. Healing process of venous ulcers: the role of microcirculation. Int Wound J 2012;10:57-64.

31. Bryan C, Knight C, Black CM, Silman AJ. Prediction of five-year survival following presentation with scleroderma: development of a simple model using three disease factors at first visit. Arthritis Rheum 1999;42:2660-5.

32. Channick RN, Simonneau G, Sitbon O, Robbins IM, Frost A, Tapson VF, et al. Effects of the dual endothelin-receptor antagonist bosentan in patients with pulmonary hypertension: a randomised placebo-controlled study. Lancet 2001;358:1119-23.
33. Rubin LJ, Badesch DB, Barst RJ, Galie N, Black CM, Keogh A, et al. Bosentan therapy for pulmonary arterial hypertension. N Engl J Med 2002;346:896-903.

34. Romaniello A, Viola G, Salsano F, Rosato E. In systemic sclerosis patients, bosentan is safe and effective for digital ulcer prevention and it seems to attenuate the development of pulmonary arterial hypertension. Rheumatology 2014;53:570-1.

35. Cozzi F, Montisci R, Marotta H, Bobbo F, Durigon N, Ruscazio M, et al. Bosentan therapy of pulmonary arterial hypertension in connective tissue diseases. Eur J Clin Invest 2006;36 Suppl 3:49-53.

36. Moore TL, Vail A, Herrick AL. Assessment of digital vascular structure and function in response to bosentan in patients with systemic sclerosis-related Raynaud's phenomenon. Rheumatology 2007;46:363-4.

37. Hughes M, Ong VH, Anderson ME, Hall F, Moinzadeh P, Griffiths $\mathrm{B}$, et al. Consensus best practice pathway of the UK Scleroderma Study Group: digital vasculopathy in systemic sclerosis. Rheumatology 2015;54:2015-24.

38. Cutolo M, Sulli A. Therapy. Optimized treatment algorithms for digital vasculopathy in SSc. Nat Rev Rheumatol 2015;11:569-71.

39. Steen V, Medsger TA Jr. Predictors of isolated pulmonary hypertension in patients with systemic sclerosis and limited cutaneous involvement. Arthritis Rheum 2003;48:516-22.

40. Bouros D, Wells AU, Nicholson AG, Colby TV, Polychronopoulos V, Pantelidis P, et al. Histopathologic subsets of fibrosing alveolitis in patients with systemic sclerosis and their relationship to outcome. Am J Respir Crit Care Med 2002;165:1581-6. 